\title{
DISCUSSION OF AN ARTICLE BY N. L. BOWEN EN- TITLED "DEVITRIFICATION OF GLASS" IN THE APRIL NUMBER OF THE JOURNAL OF THE AMERICAN CERAMIC SOCIETY. ${ }^{1}$
}

S. F. Cox: The able discussion of the question of devitrification of glass by N. L. Bowen recalls some work done on that subject by A. E. Williams and the writer. ${ }^{2}$ In a study of the effect of barium salts on the physical properties of glasses, the effect of increasing barium content on the devitrification tendency was noted.

$$
\text { Starting with a glass of the formula } 0 . \mathrm{I} \mathrm{ZnO}\} 2.5 \mathrm{SiO}_{2} \text {, }
$$

barium oxide was used to progressively replace soda, o. I mol. $\mathrm{BaO}$ replacing an equivalent amount of $\mathrm{Na}_{2} \mathrm{O}$, until all the latter had been eliminated; the zinc and potash were maintained constant throughout. A series would hence consist of six glasses of the same silica content. Seven such series of glasses were made, the silica content increasing by $0.5 \mathrm{~mol}$. in each successive series. The last glass of the series would hence have the following composition:

$$
\left.\begin{array}{ll}
0.5 \mathrm{BaO} \\
0.1 \mathrm{ZnO} \\
0.4 \mathrm{~K}_{2} \mathrm{O}
\end{array}\right\} 5.5 \mathrm{SiO}_{2}
$$

In the study of devitrification tendency, the method followed was similar to that used by Bowen. Definite heating curves were followed, the temperature being raised on successive heatings until a point well past the deformation point of most of the glasses had been attained. Fifteen of the forty-two glasses, those in the high-silica low-barium corner of the diagram, showed at $700^{\circ}$

1 J. Am. Ceram. Soc., 2, 26r (1919).

2 Trans. Am. Ceram. Soc., 18, 315-342 (1916). 
C surface devitrification which was increased upon further heating at $800^{\circ} \mathrm{C}$. All other glasses were entirely free from devitrification - those glasses which showed it did so only on the surface.

The tendency to devitrify at the surface of the glass is mentioned by Bowen, ${ }^{1}$ who states that the cause is unknown. We also made note of this tendency, but were inclined to accept the explanation of Brockbank, ${ }^{2}$ who attributes it to the volatilization of the alkali oxides from the surface, leaving a surface layer higher in silica. If the glass were nearly saturated with respect to this component, there would be a tendency for it to deposit on the surface. There would be no tendency to establish equilibrium with the glass in the interior of the piece, because of the high viscosity of the medium at these temperatures. The effect would hence be confined to the surface.

As before stated, high silica seemed more likely to produce devitrification than increasing barium content. Those glasses higher in soda, low in barium, and high in silica, tended most readily to devitrification. There was no observable connection between this property and any of the other physical properties studied.

In the light of Bowen's observations, we are inclined to believe that the reason so little devitrification was experienced in the glasses studied by us lies, among other considerations, in their high potash content and in the fact that no arsenic was used in the batches. We believe surface devitrification to have been due to the high silica content, particularly at the surface, as it occurred in those glasses highest in silica. Identification of this surface material, which was little more than a strongly adhering film, was not possible. Tendency towards crystal formation was very slow, due to the high viscosity of the glasses.

CORNING GIASS WORRS, CoRning, N. Y.

N. L. BowEN: Of the series of glasses mentioned by Mr. Cox, none has a content of barium disilicate as great as that of the corrected light barium mentioned on page $27 \mathrm{I}$. It is not surpris-

${ }^{1}$ Loc. cit., p. 277.

2 Trans. Am. Ceram. Soc., 15, 600 (1913). 
ing, therefore, that devitrification was not noted in the bariumrich members of his series. The observance of devitrification in the silica-rich members of the series was probably due to the separation of silica, not barium disilicate.

The simple explanation of surface devitrification offered by Brockbank cannot be accepted as more than a possible contributory circumstance in some glasses. I have frequently observed that devitrification begins at the surface of glasses entirely free from alkalis or any significantly volatile constituents. A crucible full of a glass containing only $\mathrm{CaO}, \mathrm{MgO}$ and $\mathrm{SiO}_{2}$ frequently shows a surface skin of crystals of forsterite, $\mathrm{Mg}_{2} \mathrm{SiO}_{4}$.

Geophysical, Laboratory,

CaRnEGIR INSTITUTION OF Washington,

Washmeton, D. C. 